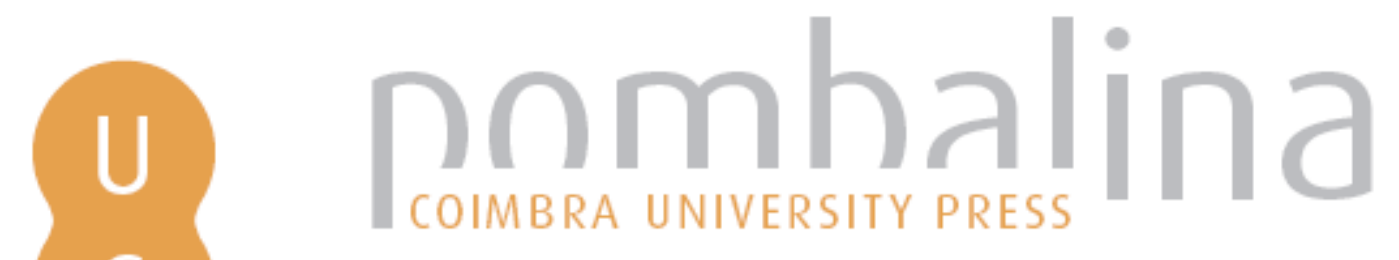

\title{
A ciência vista da literatura: e pure si muove
}

\author{
Autor(es): $\quad$ Marnoto, Rita
}

Publicado por: Imprensa da Universidade de Coimbra; Gradiva

URL

persistente: URI:http://hdl.handle.net/10316.2/32713

DOI: $\quad$ DOI:http://dx.doi.org/10.14195/978-989-26-0389-6_24

Accessed : $\quad$ 26-Apr-2023 07:02:49

A navegação consulta e descarregamento dos títulos inseridos nas Bibliotecas Digitais UC Digitalis, UC Pombalina e UC Impactum, pressupõem a aceitação plena e sem reservas dos Termos e Condições de Uso destas Bibliotecas Digitais, disponíveis em https://digitalis.uc.pt/pt-pt/termos.

Conforme exposto nos referidos Termos e Condições de Uso, o descarregamento de títulos de acesso restrito requer uma licença válida de autorização devendo o utilizador aceder ao(s) documento(s) a partir de um endereço de IP da instituição detentora da supramencionada licença.

Ao utilizador é apenas permitido o descarregamento para uso pessoal, pelo que o emprego do(s) título(s) descarregado(s) para outro fim, designadamente comercial, carece de autorização do respetivo autor ou editor da obra.

Na medida em que todas as obras da UC Digitalis se encontram protegidas pelo Código do Direito de Autor e Direitos Conexos e demais legislação aplicável, toda a cópia, parcial ou total, deste documento, nos casos em que é legalmente admitida, deverá conter ou fazer-se acompanhar por este aviso.

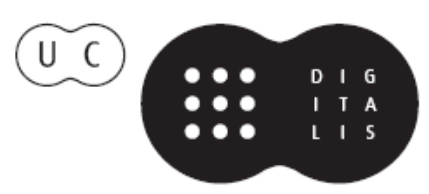


C I E N C I A I B E R T A

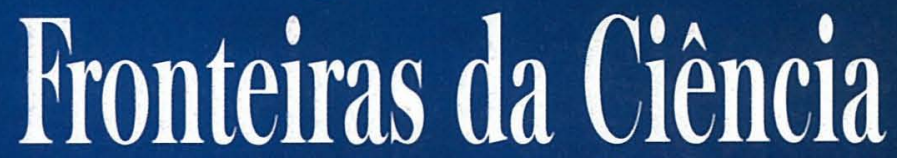

Desenvolvimentos Recentes - Desafios Futuros

RUI FAUSTO • CARLOS FIOLHAIS • JOÃO FILPE QUURRÓ

Coordenadores

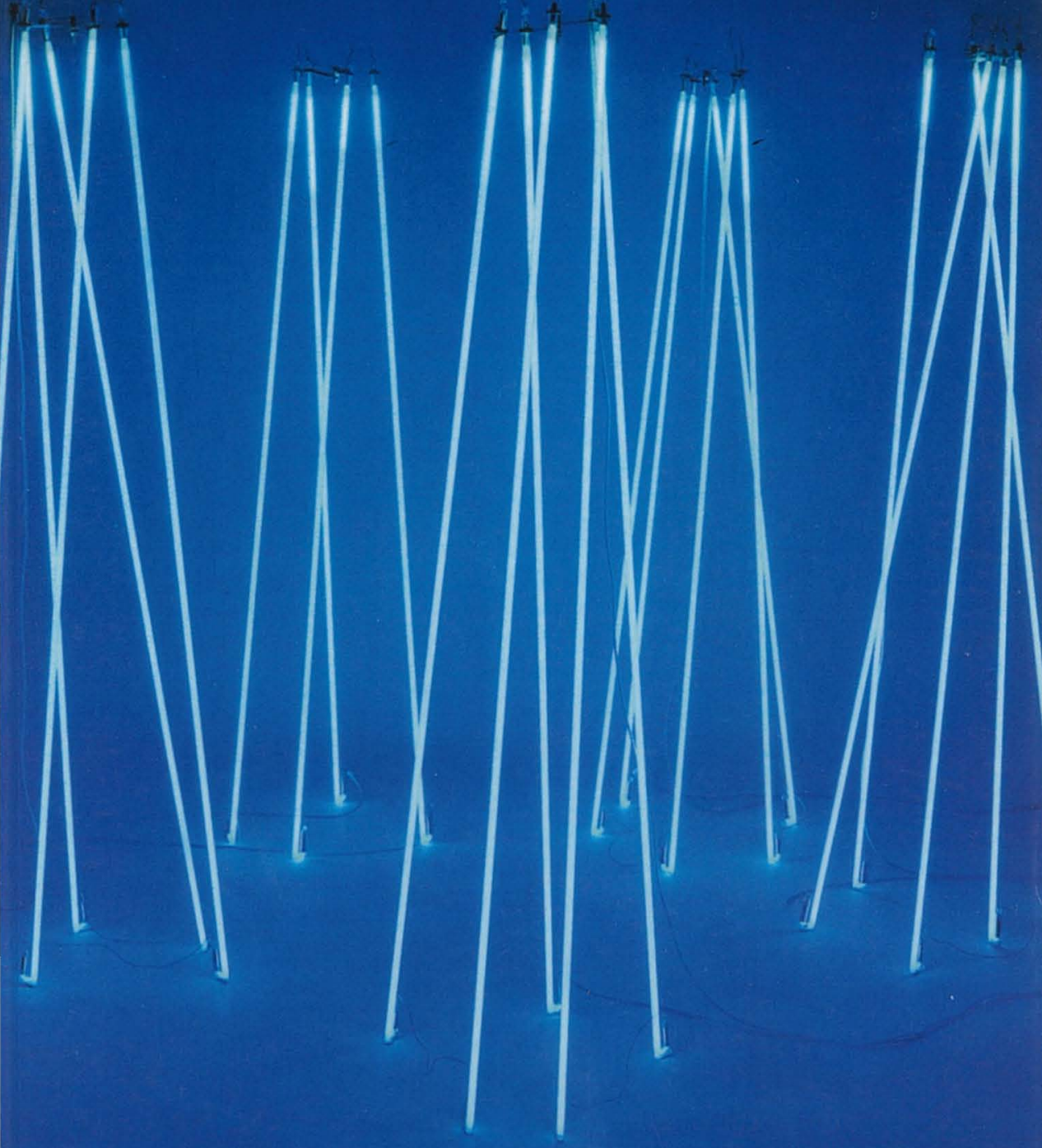

gradiva - Imprensa da Universidade de Coimbra 
(Página deixada propositadamente em branco) 


\section{RUI FAUSTO, CARLOS FIOLHAIS JOÃO FILIPE QUEIRÓ \\ Coordenadores}
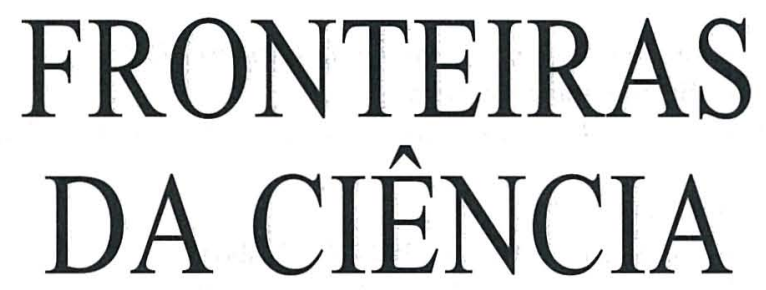

Desenvolvimentos Recentes Desafios Futuros 
(C) Gradiva - Publicações, L. da / Imprensa da Universidade de Coimbra, 2003 Coordenação editorial: Rui Fausto, Carlos Fiolhais e João Filipe Queiró Tradução: Jean Burrows, Vivien Burrows, Rui Fausto, Carlos Fiolhais e João Filipe Queiró

Revisão do texto: Isabel Pedrome

Capa: António Barros [Imprensa da Universidade. Coimbra], sobre imagem de «Águas Vivas», escultura de Silvestre Pestana, 2001

Foto: António Alves; Infografia: ESTÍMULUS [design]; Cortesia: Galeria Alvarez-Arte Contemporânea

Paginação: António Resende e Paula Isabel Jorge

Impressão e acabamento: G.C. - Gráfica de Coimbra, L. ${ }^{d a}$

Reservados os direitos para Portugal por:

Gradiva - Publicações, L. ${ }^{\text {da }}$ e Imprensa da Universidade de Coimbra

Gradiva - Publicações, L.da

Rua Almeida e Sousa, 21, r/c, esq.•1399-041 Lisboa

Telefs. $213974067 / 8 \cdot 213971357 \cdot 213953470$

Fax $213953471 \cdot$ Email: gradiva@ip.pt

URL: http://www.gradiva.pt

Imprensa da Universidade de Coimbra

Rua Antero de Quental, 195 • 3000-033 Coimbra

Telefs. 351239853110

Fax 3512398531 19・e-mail: fjrpress@ci.uc.pt

URL: http://www.imp.uc.pt

ISBN: 972-662-923-3

1." edição: Agosto de 2003

Depósito legal n. ${ }^{\circ} 199$ 463/2003 
Rita Marnoto

Faculdade de Letras

Universidade de Coimbra

\section{A ciência vista da literatura. E pure si muove}

A ciência vista da literatura, ou seja, um olhar que parte da literatura e se dirige para a ciência. O que poderá pressupor a existência de dois campos disciplinares delimitados, ciência e literatura, constituindo o primeiro o objecto observado e erigindo-se o segundo, por sua vez, em foco observador.

Há quatro séculos esta questão encontrava uma resposta genial sob a óptica de um físico, astrónomo e matemático, que foi também dotado de um profundo saber literário e de uma fina sensibilidade ao universo das palavras, Galileu. Afirma o sábio pisano, a este propósito, em Il Saggiatore:

Parece-me [...] notar no Sarsi a firme convicção de que para filosofar é necessário apoiar-se nas opiniões de algum autor célebre, de tal forma que a nossa mente, quando não se identifica com o discurso de outrem, deva ficar absolutamente estéril e infecunda; e talvez pense que a filosofia é um livro e uma fantasia de um homem, como a Ilíada e o Orlando Furioso, livros onde a coisa menos importante é que aquilo que neles está escrito seja verdade. Senhor Sarsi, as coisas não são assim. A filosofia encontra-se escrita neste grandíssimo livro que continuamente está aberto diante dos nossos olhos (quero dizer, o universo), mas não se pode entender se primeiro não se aprende a compreender a língua e a conhecer os caracteres nos quais está escrito. Está escrito em língua matemática 
e os caracteres são triângulos, círculos e outras figuras geométricas, e sem esses meios é impossivel compreender, humanamente, uma palavra que seja; sem eles, é como errar em vão por um obscuro labirinto ${ }^{1}$.

Estas considerações são dotadas de uma limpidez lucubrativa que é engrandecida pela distância no tempo. Galileu problematiza as grandes questões que, nos nossos dias, se continuam a colocar cientistas e homens de letras que cruzam os seus olhares, a saber:

1. Objectividade da linguagem científica versus investimento estético da linguagem literária.

2. Verdade científica versus ficção literária.

3. Crença na possibilidade de resolução das grandes questões que se colocam à ciência versus errância, inefabilidade.

Na verdade, os topoi em torno dos quais, muito recentemente, Hallyn ${ }^{2}$ tentava centrar a reflexão acerca dos limites entre ciência e literatura encontram-se já, in nuce, nesse passo de Il saggiatore. Mas se Galileu os definia sem hesitações de relevo, nos tempos que correm, pelo contrário,

${ }^{1}$ Galileo Galilei, Opere, a cura di Ferdinando Flora. Milão, Nápoles, Riccardo Ricciardi, 1953, p. 121: Parmi [...] di scorgere nel Sarsi ferma credenza, che nel filosofare sia necessario appoggiarsi all'opinioni di qualche celebre autore, si che la mente nostra, quando non si maritasse col discorso d'un altro, ne dovesse in tutto rimanere sterile ed infeconda; e forse stima che la filosofia sia un libro e una fantasia d'un uomo, come l'Iliade e l'Orlando furioso, libri ne' quali la meno importante cosa è che quello che vi è scritto sia vero. Signor Sarsi, la cosa non istà così. La filosofia è scritta in questo grandissimo libro che continuamente ci sta aperto innanzi a gli occhi (io dico l'universo), ma non si può intendere se prima non s'impara a intender la lingua, e conoscer $i$ caratteri, ne' quali è scritto. Egli è scritto in lingua matematica, e i caratteri son triangoli, cerchi, ed altre figure geometriche, senza i quali mezi è impossibile a intenderne umanamente parola; senza questi è un aggirarsi vanamente per un oscuro laberinto. Galileu entra em polémica com Lothario Sarsio Sigensano, pseudónimo através do qual o jesuíta Orazio Grassi assumiu a autoria da obra Libra astronomica ac philosophica, em cujas páginas tenta refutar as teses de Galileu. Como observa Flora, ao anotar o passo citado, ficam enunciados os princípios metodológicos basilares não só do pensamento de Galileu, mas também do pensamento de Kepler e Descartes, já embrionariamente contidos nos escritos de Leonardo da Vinci.

${ }^{2}$ Fernand Hallyn, «Science et Littérature: Trois Limites», Strumenti Critici, 12, 3, 1997. 
é notória a tendência para enfatizar as relações de homogeneidade que se estabelecem entre as duas áreas em causa. Na bibliografia crítica dedicada ao assunto tornou-se recorrente o uso de expressões como diluição de limites, fronteira franca entre ciência e literatura, quantificação literária, racionalidade estética, fantasia e emotividade da ciência e assim por diante ${ }^{3}$.

As novas perspectivas de investigação e as profícuas áreas disciplinares que se abriram sob os auspícios desta convivência, nomeadamente no campo das ciências humanas, não carecem de ilustração, o que acalenta o optimismo à luz do qual a cientifização da literatura bem como a literaturização da ciência têm vindo a ser consideradas. O ponto de reflexão que agora sugiro diz respeito aos riscos inerentes a essa interpenetração, tout court, quando dissociada da necessária razoabilidade crítica, a partir do momento em que uma certa hipervalorização da homogeneidade pode acabar por pôr em causa o estatuto das áreas implicadas. Recordo dois episódios que se integram reciprocamente.

Nos anos 60, vastos sectores da crítica literária, divulgados, em particular, por via francesa, instituiram uma metodologia de abordagem do fenómeno literário que postulava a sua definição com base em critérios que se pretendiam objectivos, desenvolvendo premissas estruturalistas e formalistas. Esta metodologia crítica elegeu como objecto de estudo a

3 Considere-se, a título de exemplo, a proximidade entre beautiful science e beautiful criticism, tal como é exposta por Arthur C. Danto, «Beautiful Science and the Future of Criticism», in The Future of Literary Theory, edited by Ralph Cohen, Nova Iorque, Londres, Routledge, 1989. É nestes termos que David Botstein caracteriza a beautiful science: First, the confrontation of the human mind with a natural phenomenon, then its investigation through observations and experiments, the continual proposal of theories, the testing of predictions, and finally, in the best case, the convincing demonstration of the validity of one of the theories through confirmation of its specific predictions. The process can take only a few years and involve only a few scientists or it can span centuries and involve many. The practical consequences may be revolutionary and change the course of history (for example special relativity) or it may have little or no use. In either case, a full scientific story, especially one that has been unfolding over historic times, can be a lovely thing, like a classical symphony or a gothic cathedral (p. 370). A partir destas premissas, Danto leva a cabo um confronto entre as bases metodológicas da beautiful science e da crítica literária, concluindo que os paradigmas que enformam a primeira de há muito servem de matriz à segunda. 
literariedade, enquanto categoria através da qual seria possível uma definição válida e abrangente da literatura. Abstracção feita do contexto histórico e das implicações culturais do texto, é conferida primordial importância à configuração material da mensagem, ao código linguístico e à célebre função poética.

Uma tal tentativa de remeter o literário para o plano formal gerou muitos equívocos, em virtude do seu carácter redutor. A literatura não é uma manifestação acultural e a-histórica. Além disso, qualquer texto literário decorre da intersecção de vários códigos heterogéneos, um dos quais é o linguístico. Como mostrou Lotman, a literatura é um sistema de modelização secundário, que tem na sua base um sistema de modelização primário, ou seja, uma língua natural ${ }^{4}$.

Desta feita, a transposição de uma metodologia pretensamente objectiva para o âmbito da crítica literária não serviu nem os adeptos da exactidão, para quem a literatura continuou a escapar ao domínio do quantificável, nem os homens de letras, que sentiram o seu campo invadido por uma modalidade de pesquisa exógena.

Este capítulo dos estudos literários reflecte-se, em contraluz, nos riscos comportados por certo alheamento das ciências relativamente a critérios de objectividade, tal como resultaram do embuste montado por Sokal ${ }^{5}$.

O físico matemático Alan Sokal propôs à revista Social Text a publicação de um artigo no qual engendrava um discurso intencionalmente enganoso acerca de questões científicas. O texto, dotado do enigmático título Transgressing the boundaries - toward a transformative hermeneutics of quantum gravity, foi prontamente aceite pelos editores, tendo sido publicado no número da Primavera / Verão de 1996. O embuste foi depois revelado pelo próprio autor, num artigo vindo a lume numa outra revista, Lingua Franca, no número de Maio / Junho do mesmo ano. Em sua opinião, o artigo de Social Text, deliberadamente recheado de

${ }^{4}$ A reunião dos segmentos do texto uns com os outros, a formação de sentidos suplementares que daí resulta segundo o princípio de transcodificação interna e o nivelamento dos segmentos do texto, transformando-os em sinónimos estruturais e formando sentidos complementares segundo o princípio de transcodificação externa, constituem o fundamento do mecanismo do texto artístico. (Iuri Lotman, A Estrutura do Texto Artístico. Lisboa, Estampa, 1978, p. 148).

5 Para uma apresentação detalhada das circunstâncias envolvidas e um comentário crítico, ver Steven Weinberg, "Sokal's Hoax», in The New York Review, 8/8/1996. 
citações e remissões para destacados pensadores da pós-modernidade, só teria recebido o beneplácito do corpo editorial por ir ao encontro dos pontos de vista por ele genericamente partilhados.

Note-se, porém, que algumas das observações nele contidas situam o leitor no perfeito ambiente de uma narrativa de Borges, como acontece no momento em que Sokal afirma que o $\pi$ de Euclides e o $G$ de Newton, formalmente concebidos enquanto constantes e universais, são hoje compreendidos na sua inelutável historicidade. $\mathrm{O}$ autor de «Transgressing the boundaries» desafia a vigilância da comunidade científica, pondo à prova a sua capacidade de distinguir os verdadeiros avanços no conhecimento de certas panaceias que se mascaram através de uma linguagem codificada. Mas os apreciadores das belas-letras não ficarão menos perplexos do que os mestres da ciência ao serem confrontados com o facto de, para se deliciarem com a leitura de uma empolgante narrativa fantasiosa, terem de folhear as páginas de uma revista científica.

A evocação destes dois episódios pretende mostrar que a transposição de saberes e o intercâmbio entre ciência e literatura não é empresa susceptível de ser levada a cabo de ânimo leve. Entre a negação da índole subjectiva do conhecimento científico (recordem-se Andrew Ross e Bruno Latour) e o alargamento desmesurado do campo de incidência da estética e da literatura, situa-se a necessidade de uma reflexão acerca da configuração das fronteiras que unem os dois campos, na sua especificidade.

Retomemos, pois, os três topoi já problematizados por Galileu.

\section{OBJECTIVIDADE DA LINGUAGEM CIENTÍFICA VERSUS INVESTIMENTO ESTÉTICO DA LINGUAGEM LITERÁRIA.}

A actividade científica é inalienável de uma linguagem natural que a traduza enquanto sistema de modelização primário, quer porque a relação entre sujeito e objecto requer uma mediação sígnica, quer em virtude das implicações institucionais da ciência. É neste sentido que Merton define quatro imperativos pressupostos pela sua estrutura cultural: universalismo, comunismo, desinteresse e cepticismo organizado ${ }^{6}$.

${ }^{6}$ Robert K. Merton, The Normative Structure of Science "Culture and Society. Contemporary Debates», edited by Jeffrey C. Alexander, Steven Seidman, Cambridge University Press, 1990. 
A linguagem introduz uma mediação que não pode deixar de se confrontar com os desígnios de objectividade visados pela ciência. Se os signos simbolizam, simulam, facto é que as palavras também servem para mentir ${ }^{7}$. $\mathrm{Na}$ verdade, a ligação entre o signo e o objecto que designa não é motivada, porquanto assente no carácter institucionalizado do sistema linguístico que actualiza, como o mostrou Saussure, e no papel desempenhado pelo interpretante, nos termos da teoria linguística desenvolvida por Peirce.

As repercussões deste dado de facto sobre a linguagem científica não são de somenos importância. Haraway ${ }^{8}$ estudou algumas redes metafóricas através das quais, no discurso científico, têm vindo a ser expostas várias teorias acerca do funcionamento do sistema imunológico: recurso a imagens heróicas e bélicas transpostas do Star Wars e da ficção de uma invasão extraterrestre, com células killer e tanks nos principais papéis; personificação do corpo humano numa immunological orchestra, dirigida por um maestro, cujos componentes biológicos se agregam de forma a interpretar partes específicas; e até paralelos com o célebre fantasminha do cinema e da banda desenhada, Casper. Neste âmbito, a linguagem passa a ser modelizada de tal forma que se gera um terreno de areias movediças entre sistemas de modelização primários e sistemas de modelização secundários.

John Locke é peremptório, a este propósito, ao afirmar:

A partir do momento em que o espírito e a fantasia agradam mais ao mundo do que a pura verdade e do que o efectivo conhecimento, o uso do discurso figurado e da alusão dificilmente serão considerados como imperfeição ou abuso. Confesso que, quando se pretende, em particular, encantar e divertir, mais do que informar ou contribuir para um aperfeiçoamento, tais ornamentos, assim tomados de empréstimo, não devem ser tidos, propriamente, por erro. Contudo, se queremos representar as coisas

${ }^{7}$ Mentirosos por vocação são, segundo Umberto Eco, os poetas: Mentitori per vocazione, più che coloro che dicono come l'essere è, essi sembrano essere coloro che non solo ne celebrano la necessità, ma spesso si (e ci) concedono di negarne le resistenze - perché per essi le tartarughe possono volare, e persino possono apparire esseri che si sottraggono alla morte. (Kant e l'Ornitorinco, Milão, Bompiani, 1997, p. 42); Mentirosos por vocação, mais do que aqueles que dizem como o ser é, parecem ser aqueles que não só celebram essa necessidade, mas muitas vezes se (e nos) permitem negar as resistências a fazê-lo - porque para eles as tartarugas podem voar, e até podem aparecer seres que escapam à morte.

${ }^{8}$ Donna J. Haraway, «The Bio-Politics of Post-Modern Bodies: Constitutions of Self in Immune System Discourse», Simians, Cyborgs and Women. The Reinvention of Nature, Londres, Free Association Books, 1995 [reprint]. 
como elas são, devemos reconhecer que toda a arte da retórica e todos os ornamentos artificiais e figurativos das palavras, inventados pela eloquência, ao superarem a ordem e a clareza, não servem senão para insinuar falsas ideias, para desencadear paixões e, além disso, para confundir o juizo crítico. Por consequência, são perfeitos enganos: e, porém, apesar de a oratória os considerar louváveis e recomendáveis em arengas e em intervenções populares, devem ser absolutamente evitados em todos os discursos que tenham por objectivo informar ou instruir. Quando a verdade $e o$ conhecimento estão em causa, de modo algum podem deixar de ser um grande erro, quer do estilo da linguagem, quer da pessoa que os usou'.

\section{VERdAdE CIENTÍFICA VERSUS FICÇÃo LITERÁRIA.}

A distinção preconizada por Galileu entre a verdade científica, por um lado, e a fantasia da Iliada e do Orlando Furioso, por outro, suscita um questionamento de ambas as margens da corrente.

Na Poética, Aristóteles diz que a obra do poeta não consiste em contar coisas que realmente aconteceram, mas que possam acontecer, possiveis do ponto de vista da verosimilhança ou da necessidade. Aliás, qualquer obra literária implica um pacto de referencialidade entre autor e leitor, o que deixa em aberto a possibilidade de que também o escritor assuma a verdade do contado.

É o próprio Camões quem, numa das estâncias iniciais de Os Lusiadas, refuta o fingimento do Orlando Furioso, a mesma narrativa em oitavas que Galileu apresentava como exemplo de um relato fantasioso:

Ouvi, que não vereis com vãs façanhas,

fantásticas, fingidas, mentirosas,

louvar os vossos, como nas estranhas

musas, de engrandecer-se desejosas:

as verdadeiras vossas são tamanhas

que excedem as sonhadas, fabulosas, que excedem Rodamonte e o vão Rugeiro

e Orlando, inda que fora verdadeiro ${ }^{10}$.

9 John Locke, An Essay Concerning Human Understanding, Londres, Routledge, 1955, 3. 10. 34., p. 411.

10 Luís de Camões, Os Lusíadas, Leitura, prefácio e notas de Álvaro Júlio da Costa Pimpão, Lisboa, Ministério da Educação, 1989, 1. 11., p. 3. 
Neste contexto, a fronteira entre as duas margens poderia ser esclarecida através da noção de mundo possível, componente essencial do universo da ficção:

Os mundos ficcionais mantêm sempre uma correlação semântica com o mundo real, correlação essa que oscila entre a representação mimética e a transfiguração desrealizante. Seja como for, a verdade dos objectos ficcionais não se funda na correspondência com o real: só pode ser equacionada em função do mundo possivel instituído pelo texto ${ }^{11}$.

Mas, sob este ponto de vista, é o campo da ciência que passa a aproximar-se do da literatura. De facto, o caminho para a verdade científica passa pela formulação de hipóteses, as quais, até ao momento em que são confirmadas ou infirmadas, se apresentam como mundos possíveis, ou seja, mundos ficcionais que mantêm sempre uma correlação semântica com o mundo real. As leis da queda livre e da aceleração foram concebidas por Galileu a partir de uma idealização das experiências que realizou, conforme ele próprio declara no Dialogo dei Massimi Sistemi ${ }^{12}$.

\section{CRENÇA NA POSSIBILIDAdE DE RESOLUÇÃO DAS GRANDES QUESTÕeS QUE SE DEPARAM À CIÊNCIA VERSUS ERRÂNCIA, INEFABILIDADE.}

A ciência incide sobre um conjunto de problemas para os quais entende ser possível encontrar uma solução, reconhecendo, porém, a existência de problemas que, num determinado estádio, são dados por não resolúveis, e que, portanto, valem como questões em aberto. Essa área, relegada para o campo da imaginação, tem sido comparada, a partir de fundamentos nem sempre dotados de particular consistência, com a experiência poética.

Conjuntos infinitos, conjuntos infinitos não contáveis, variedades de dimensão infinita, curvas que preenchem o espaço - [...] objectos definidos, com propriedades definidas, algumas conhecidas, muitas desconhecidas. Estes objectos não são físicos ou materiais. Eles existem fora do espaço e do tempo da existência física. Cognoscível e não cognoscível, num movimento [...] qui ne se contente pas de la fuite éperdue, fût-elle panique, et garde ainsi le pouvoir de s'y dérober. A primeira citação foi extraída de A Experiência Matemática, de Davis e

11 Carlos Reis e Ana Cristina M. Lopes, Dicionário de Narratologia. Coimbra, Almedina, 1994, $4 .^{\text {a }}$ ed. revista e aumentada, p. 245.

12 Fernand Hallyn, Science et Littérature, pp. 371-373. 
Hersh ${ }^{13}$. Insere-se num passo em que os autores do livro se referem à concepção dos objectos matemáticos segundo a perspectiva do platonismo. A segunda citação foi extraída da obra de Maurice Blanchot, L'Entretien Infini. Observa Blanchot acerca da palavra poética:

A palavra é esta viragem. A palavra é o lugar da dispersão, desarrumando e desarrumando-se, dispersando e dispersando-se para além de todos os limites. É que a palavra que proporciona a fuga e se faz fuga na fuga preserva, na própria fuga, este movimento de ocultação que não se contenta com a fuga desvairada, mesmo que seja pânica, conservando assim o poder de se ocultar ${ }^{14}$.

Tal como o cognoscível se desdobra no não cognoscível e a palavra no silêncio, assim é [...] in questo grandissimo libro che continuamente ci sta aperto innanzi a gli occhi (io dico l'universo) [...] [i cui] caratteri son triangoli, cerchi, ed altre figure geometriche que a ciência está escrita e é lida ${ }^{15}$.

O universo como uma grande biblioteca, conforme Borges bem poderia explicar a Galileu:

A Biblioteca existe ab eterno. Dessa verdade cujo corolário imediato é a eternidade futura do mundo, nenhuma mente razoável pode duvidar. O homem, o imperfeito bibliotecário, pode ser obra do acaso ou dos demiurgos malévolos; o universo, com a sua elegante dotação de estantes, de tomos enigmáticos, de infatigáveis escadas para o viajante e de latrinas para o bibliotecário sentado, só pode ser obra de um deus ${ }^{16}$.

Então Galileu responderia: E pure si muove.

13 Philip J. Davis, Reuben Hersh, A Experiência Matemática, Lisboa, Gradiva, 1995, p. 299.

14 Maurice Blanchot, L'Entretien Infini, Paris, Gallimard, 1995, p. 30.

15 Galileo Galilei, Opere, p. 121; cf. supra, n. 1.

16 Jorge Luis Borges, La Biblioteca de Babel, Prosa Completa 2. Historia de la Eternidad. Ficciones. El Aleph, Barcelona, Buenos Aires, Brugera, Emecé, 1985 , p. 156. 
 \\ A palavra "fronteiras" pode ser tomada em} diferentes sentidos. Pode referir-se aos limites, necessariamente provisórios, entre o conhecido e o desconhecido, ou aos limites entre o possivel e o impossivel, e, dentro do possivel, entre o desejável e 0 indesejável. Fronteiras podem também ser as delimitações, nem sempre nítidas, entre ciência e não-ciência, e dentro da ciência, entre as várias disciplinas. Quais são então as fronteiras da ciência?

Neste livro, a resposta a esta pergunta é dada, segundo as mais diferentes perspectivas, por um conjunto notável de personalidades, cientistas ou não, entre as quais se contam três Prémios Nobel.

Rui Fausto, Carlos fiolhais e JoÃo Fillipe Queiró são, respectivamente, professores de Química, Física e Matemática na Faculdade de Ciências e Tecnologia da Universidade de Coimbra. 